\title{
The Powder-pack Boriding and Nitriding Process: Microstructural Characterization of Boride and Nitride Layers on ARMCO Pure Iron
}

\author{
M. Ortiz-Domínguez ${ }^{1}$, I. Simón-Marmolejo ${ }^{1}$, M. Elias-Espinosa ${ }^{2}$, M. A. Flores-Rentería ${ }^{1}$, L. E. \\ Martínez-Martínez ${ }^{1}$ and A. Arenas-Flores ${ }^{1}$ \\ 1. Department of Mechanical Engineering, Universidad Autónoma del Estado de Hidalgo-Campus \\ Sahagún, Hidalgo, México. \\ 2. School of Engineering and Sciences, Tecnológico de Monterrey, Ciudad de México, México.
}

Surface hardening, a process that includes a wide variety of techniques (Carburizing, Nitriding, Nitrocarburizing, Boriding, and Thermal diffusion process), is used to improve the wear resistance of parts without affecting the more soft, tough interior of the part [1-3]. In particular, resistant layers of borides are produced in ferrous and no-ferrous materials though the well-developed process of boriding. In ferrous materials, this thermochemical diffusion treatment generally possesses superior hardening features than those found in conventional processes like carburizing, nitriding or chromising, due to the formation of single $\mathrm{Fe}_{2} \mathrm{~B}$ or a double $\left(\mathrm{FeB}+\mathrm{Fe}_{2} \mathrm{~B}\right)$ hard phases. On the other hand, the thermochemical process of nitriding is also used to improve the wear and corrosion resistance of engineering components, producing a hard case and a soft and tough core. Nevertheless, significant variation has been identified in the hardness gradient resulting in ablated tribological performances. To mitigate the brittleness and those variations in microhardness, two multicomponent surface treatments such as boronitriding are being investigated. Nonetheless, very little work has been devoted to assess both the microstructural and mechanical characteristics of boron nitride coatings on ferrous materials [4-5]. In this study, the microstructure of the $\varepsilon-\mathrm{Fe}_{3} \mathrm{~N}$ and $\mathrm{Fe}_{2} \mathrm{~B}$ layers formed on an ARMCO pure iron surface have been investigated at different temperatures by the powder-pack process.

Cubic commercial samples were cut from an ARMCO iron bar with composition: $\mathrm{Mn}, 800$ ppm; $\mathrm{C}$ and $\mathrm{P}, 200 \mathrm{ppm}$; and S, $150 \mathrm{ppm}$. The substrate pure iron used in this work was selected to curb the effect of alloying elements in order to solely analyse the characteristic boride and nitride layers and some of their mechanical effects. The boro-nitriding treatment was carried out in two stages: boriding and then nitriding. Powder-pack boriding and powder-pack nitriding procedures were preferred in this study for its cost-effectiveness, and simplicity of the required equipment. The samples were embedded in a closed in a closed cylindrical case (AISI 304L stainless steel) having a boron powder mixture inside with an average particle size of $30 \mu \mathrm{m}$. The boriding agent contained an active source of boron $\left(\mathrm{B}_{4} \mathrm{C}\right)$, an inert filler $(\mathrm{SiC})$, and an activator $\left(\mathrm{KBF}_{4}\right)$. The powder-pack boriding process was carried out in a conventional furnace under a pure argon atmosphere at 1223 and $1273 \mathrm{~K}$ for $8 \mathrm{~h}$ of exposure for each temperature. Once the boriding treatment was finished the container was removed from the furnace and slowly cooled to room temperature. In the second step, the pre-boriding iron samples were nitrided by the pack method in the powder mixture consisting of calcium cyanamide $\left(\mathrm{CaCN}_{2}, \sim 24 \%\right.$ of $\left.\mathrm{N}\right)$ and calcium silicate ( $\mathrm{CaSi}, \sim 35 \mathrm{wt} \%$ of the mixture) as an activator. The samples were directly immersed in the powder mixture in another stainless steel cylindrical case. The nitriding temperatures were $773 \mathrm{~K}$ and 823 for $8 \mathrm{~h}$ using the same furnace and conditions. The depth of the surface coatings and morphology were analysed by SEM and EDS (JEOL JSM-6360 LV at $20 \mathrm{kV}$ ). The distribution of alloying elements across the multicomponential coating was measured using the GDOES technique utilising a Horiba Jobin Yvon RF GD. X-Ray Diffraction (XRD) analyses of the layers were carried out with $2 \theta$ varying $20^{\circ}$ to $90^{\circ}$, using $\mathrm{CuK}_{\alpha}$ radiation and $\lambda=1.54 \AA$. Figure 1 shows the cross-sections and 
the EDS analysis obtained by SEM at the $\varepsilon-\mathrm{Fe}_{3} \mathrm{~N} / \mathrm{Fe}_{2} \mathrm{~B}$ interphase for the borided ARMCO pure iron. The corresponding profile composition revealed maximum nitrogen content on the surface of 39.9 at $\%$ $\mathrm{N}$ (Fig. 2). The existence of the $\varepsilon-\mathrm{Fe}_{3} \mathrm{~N}$ and $\mathrm{Fe}_{2} \mathrm{~B}$ were verified by $\mathrm{X}$-ray diffraction (Fig. 3). These results demonstrate that the nitride phase strengthen the outer, poorly resistant part of the boride layer (microhardness and tribological behaviours). No delamination or spallation failures for long sliding distances and with very low friction fluctuations were obtained by the boronitrided surface.

References:

[1] A. Graf von Matuschka in "Boronizing", $1^{\text {st }}$ ed. (Carl Hanser Verlag, Munich) p. 12.

[2] J. R. Davis in "Surface Hardening of Steels: Understanding the Basics", 1 st ed. (ASM, Ohio) p. 213.

[3] K. H. Habig, Mater. Eng. 2 (1980), p. 83.

[4] Y. A. Balandin, Met. Sci. Heat Treat. 46 (2004), p. 385.

[5] W. D. Man et al, Surf. Coat. Technol. 171 (2003), p. 241.

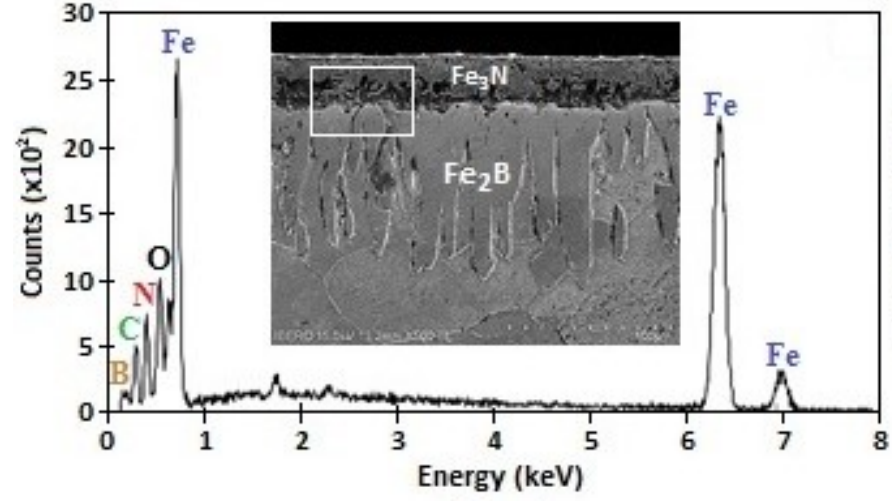

Fig. 1

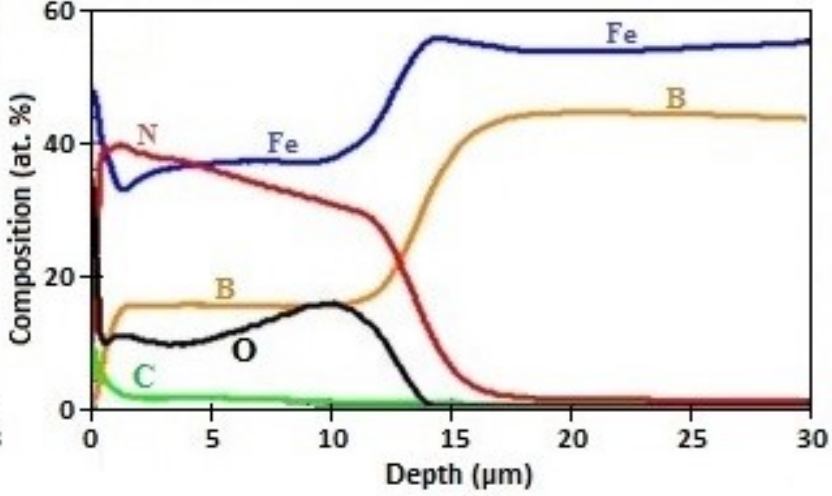

Fig. 2

Figure 1. Image (SEM) cross-sectional of boro-nitrided ARMCO pure iron showing the produced layers and GDOES

Figure 2. spectrum of the elements distribution from the surface to the interior of the nitride $\left(\gamma^{\prime}-\mathrm{Fe}_{4} \mathrm{~N}_{1}\right.$ x) at $823 \mathrm{~K}$ with $8 \mathrm{~h}$, and boride $\left(\mathrm{Fe}_{2} \mathrm{~B}\right)$ layers at $1273 \mathrm{~K}$ with $8 \mathrm{~h}$.

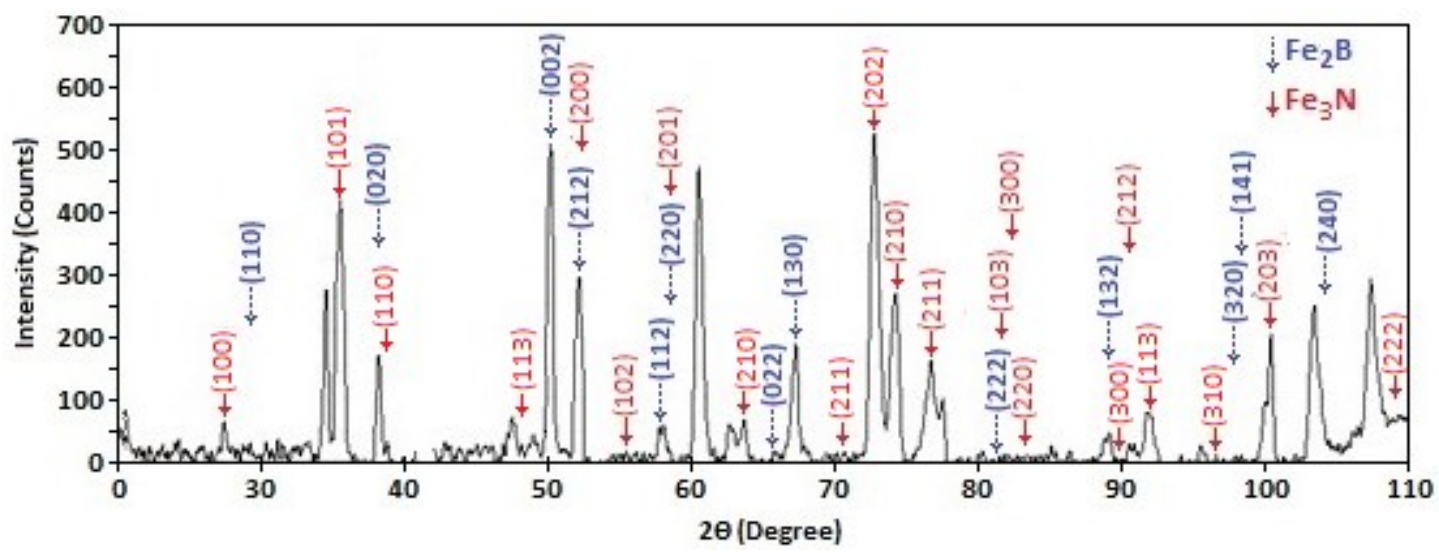

Figure 3. X-ray diffraction patterns obtained at the surface of boro-nitrided pure iron exposed to the boriding conditions of $1273 \mathrm{~K}$ with $8 \mathrm{~h}$; and nitriding conditions of $823 \mathrm{~K}$ with $8 \mathrm{~h}$. 